\title{
LA CRÍTICA CONTEMPORÁNEA DE ARTES VISUALES EN AMÉRICA LATINA: ¿IMPUGNACIÓN DEL EUROCENTRISMO?
}

\author{
Guadalupe Alvarez de Araya Cid
}

Lo que expondré a continuación no pretende ni con mucho constituir una exposición acabada de los procesos que van acompañando y articulando la transformación epistemológica en el terreno de la crítica de artes en América Latina. Más bien intentaré presentar un conjunto de rasgos sintomáticos que pienso no es posible soslayar cuando se discuten estas cuestiones.

En este sentido, tengo la impresión de que sólo muy recientemente han ingresado a la disciplina de la Historia los modelos postestructuralistas y deconstructivistas que sostienen a las nuevas orientaciones epistemológicas. En cambio, el terreno de la Crítica de Artes ha constituido desde temprano terreno fértil para tales orientaciones y no parece haber engendrado más comentarios que aquel atribuido al cambio generacional. En cierto sentido, ello puede interpretarse como que esta nueva crítica habría realizado el proyecto de àctualización epistemológica y se habría integrado sincrónicamente a los procesos europeos y estadounidenses. Sin embargo, es el terreno de las Ciencias Sociales el que ha vivido con mayor intensidad este proceso desde el momento de que ha visto surgir al menos tres orientaciones emparentadas con ellas: los Estudios Culturales, los Multiculturalismos y los Poscolonialismos. La crítica de artes visuales y la crítica literaria, por su parte, que han vivido desde la década de los cincuentas un proceso 'contaminante' con las Ciencias Sociales parecen haber participado activamente en el surgimiento de estas orientaciones, en la medida en que ven fundirse en su interior campos categoriales que, inicialmente, pertenecían a su esfera reflexiva.

No obstante, si la década de los ochenta se caracterizó -tanto en Europa como en América Latina- por una fuerte disputa en torno a la condición posmoderna y, por extensión. en torno a la función del intelectual que ella comporta para América Latina', en los últimos años pareciera desarrollarse una reflexión similar en torno al sentido de los aparatos epistemológicos que ese giro del pensamiento ha puesto en funcionamiento. De modo similar, pareciera que el núcleo de esta discusión -sobre aparatos que aparentemente sostienen una voluntad de 'impugnación del zurocentrismo'- se concentrara en dos grandes tipos de problemas; a saber: las reformulaciones $\therefore$ ategoriales que permiten suponer un poderoso movimiento integratorio de disciplinas procedentes de diversas esferas de la razón, en un esfuerzo por explicitar los sentidos de ese movimiento -y sus implicancias para América Latina, claro está-, por un lado, y, por otro, las implicancias políticas de la asunción de tales aparatos.

Recuérdense, por ejemplo, la recopilación de Hal Foster: La postmodernidad, Kairós. Barcelona. 1985 (1983) o aquella de la CLACSO. 
Desde este ángulo, me parece que los puntos de vista expuestos por Agustín Martínez en Metacrítica ${ }^{2}$, ofrecen un punto de partida y un sustento metodológico para una problemática que, según se desprende de lo anterior, encuentra en la pregunta por el método un excelente eje para su reflexión.

Allí, Martínez examina los sentidos y estrategias de la crítica literaria entre 1965 y 1975. aproximadamente, según las cuales el proceso de consolidación y de revisión de la crítica se operó sobre el debate en torno a la conciencia, por parte de la crítica, de la transformación de su objeto. Esa transformación del objeto literario -cuyo sentido principal era la transformación del lenguaje que la informaba- y que se interpretó como una 'crisis de la crítica', parecía desplegarse en el marco del boom literario. La densidad epistemológica del fenómeno transformatorio del objeto literario en el marco específico del boom. condujo a amplios sectores de la crítica a examinar sus aparatajes cognoscitivos y a poner en duda sus premisas críticas, en particular, el andamiaje teórico con que hasta ese entonces se había construido la posible 'identidad latinoamericana'.

Ahora bien, no cabe duda que ese marco en el que la crítica examina sus posiciones, es decir, la idea de que 'dará a luz' un otro momento o, dicho de otra manera -y que pareciera ser la intención de Martínez-, esa crisis supone un pivote en las tradiciones epistemológicas y en los modos de la experiencia en América Latina que no puede ser otro que el giro del capital hacia lo que se ha denominado 'capital tardío' y a las dinámicas de globalización de la cultura que imponen a la idea misma de 'identidad'. en tanto unidad, un serio revés y que, por lo tanto, obligan a replantear sus fundamentos en un movimiento que implica la revisión de las mismas disciplinas que la observan. Como todos sabemos ese giro comenzó su verificación precisamente en el momento en que en la Metrópoli está tomando lugar la disputa en tomo a la sociedad de consumo y, en América Latina, se está girando desde la matriz 'América Latina, continente joven' a aquella de 'América Latina, continente subdesarrollado's y que alcanzó su punto cúlmine en la Teoría de la Dependencia. En el nuevo escenario parece imprescindible retomar el esfuerzo teórico de la década del sesenta y del primer lustro del setenta, con miras a redefinir un conjunto de categorías que, al mismo tiempo que en algunos críticos se dan por sentado ${ }^{+}$, en otros parecen disolverse en una exigencia de mayor subjetividad que dificulta la operatividad misma del régimen de producción intelectual. En este sentido, se ha pretendido establecer una cierta sinonimia entre postmodernidad y disolución del sujeto por la vía de la integración disciplinar, afirmación que implica la realización parcial del proyecto moderno en cuanto hegemonía de la razón instrumental.

En efecto, resultan significativos los trabajos de integración artístico-críticos que, en la década del setenta y primeros años de los ochenta, fueran llevados adelante por Jorge Glusberg en la Argentina, Frederico Morais en el Brasil o Nelly Richard en Chile. En ellos, observamos una estrategia de identificación poética entre el ejercicio crítico y su objeto, cuestión que pareciera estar simultáneamente ofreciendo una respuesta a la pregunta por el método (en el sentido de asumir una identidad lingüística, que por otro lado aún no resulta clara) y reforzando asimismo la constitución de un sistema artístico que se observa frágil y nunca plenamente consolidado, por una parte, pero que por otra, desdibuja y desencaja la actividad crítica.

Pero quizás lo más relevante de esta discusión en torno a la asunción de estos nuevos aparatajes, sea el sentido mismo de lo que pudiera llamarse 'eurocentrismo'. Si descontamos el hecho de que América Latina es impensable por fuera del marco occidental impuesto por Europa, por otro es impensable una Europa o un Occidente que no incluya a América Latina: tanto en lo que puedan ser las modalidades y caminos de su asunción de sí como en lo que respecta al rol

\footnotetext{
'Martíncz. Agustín: Metacrítica. Lniversidad de los Andes. Mérida. 1996.

'Cándido. Antonio: 'Literatura y subdesarollo' en América Latina en su literatura. Siglo XXI. México. 1976. citado por Martínez en Op. Cit.

+ Me refiero, por ejemplo, a la imprecisión y ambiguedad con que se subsumen procesos y condiciones extremadamente complejos bajo el rótulo dialéctica centro-periferiá
} 
económico y político que, para Europa, le ha sido asignado a América Latina ${ }^{5}$. Por ello, me parece que lo más significativo del examen de Martínez antes citado, sea sin lugar a dudas la noción pragmática de lenguaje que da cuerpo material a su presentación de esa década y de los procesos en el campo de la crítica literaria y, por extensión a otros terrenos disciplinares. En efecto, la lectura de Martínez supone un régimen de producción intelectual que hace posible la Universidad. El régimen de producción universitario se constituye entonces no sólo en un espacio de conformación de personal más o menos capacitado que ha logrado integrar una lógica productiva $^{16}$ más o menos actualizada, sino ante todo en el nuevo polo de religación interna ${ }^{17}$.

El ingreso de los nuevos aparatos epistemológicos procedentes del Postestructuralismo y el Deconstructivismo ${ }^{8}$ desestiman desde su interior las categorias analíticas que hicieron posible ese régimen de producción. No sólo me parece evidente el hecho de que los Estudios Culturales y los Multiculturalismos surgen al interior de sociedades postindustriales, sino que ha sido la crítica anglosajona la que se ha concentrado en ellos con mayor interés, y que han sido las universidades estadounidenses las que, ya sea por la vía de intercambios académicos o de apoyo a la investigación sobre América Latina, ha traído a nuestro segmento continental tales enfoques. Pero, asimismo, no es posible desconocer el hecho de que los lugares desde los cuales se iniciara ese plegamiento, y que han contribuido a su expansión por América Latina, la constituyen precisamente aquellos núcleos de intelectuales ligados por la diáspora impuesta por las dictaduras militares de mediados de los años setenta. En este sentido, es necesario señalar que de algún modo ese giro puede inscribirse en las estrategias encriptadoras del discurso intelectual en los regímenes autoritarios, como señalara en su momento Nelly Richard.

En un período que no supera los diez años hemos visto un acelerado plegamiento de los equipos intelectuales latinoamericanos 'de relevo' hacia esos enfoques; en un sentido más o menos cronológico, tales enfoques oscilaron desde los más amplios Estudios Culturales en la década de los ochenta, hacia los más circunscritos Multiculturalismos y Poscolonialismos en los noventa. Si los primeros exageraban la tendencia de la crítica de los setenta hacia una fusión con las Ciencias Sociales, los segundos pretenden conducir esa tendencia hacia la determinación identitaria de pequeñas unidades culturales al interior de agrupamientos más abstractos, como aquel de nación.

Constituye, por otra parte, rasgo sintomático de ese movimiento el que, desplazando la 'constitución del objeto por la crítica', que asumía su mediación de su objeto, hacia la 'asunción al-pie-de-la-letra de la naturaleza lingüística del objeto', haya trasladado el examen de las especificidades culturales a un plano simbólico que, al incorporar instrumentales procedentes de la psicología postestructuralista, supone a lo real, para la conciencia, sometido prioritariamente a fuerzas irracionales que en última instancia privilegian la acción individual -reducida por otro lado a la impotencia- por sobre los movimientos comunitarios que quedan desautorizados bajo el supuesto de no representar, por su propia naturaleza, las ambiciones individuales. En un sentido más general, este aspecto ha incidido en la detección de múltiples especificidades culturales cuestión que en sí misma no nos parece negativa, antes al contrario- que, bajo la apariencia de un oponerse a la tradición teórica de la identidad latinoamericana (tradición que disolvería esas especificidades culturales) en la práctica atentan contra la realización misma del proyecto identitario. De hecho, es vox populi que Frederico Morais se refirió a esa ambición como forma

\footnotetext{
Véase Quijano, Aníbal: 'Modernidad, identidad y utopiáa:

Entendemos por 'lógica productiva' las relaciones entre los momentos metodológicos y las transformaciones que el objeto experimenta en un régimen de producción específico. que por cierto no se expresa tan sólo en los límites disciplinares; es decir, no tan solo a las relaciones más o menos identitarias entre método yobjeto. sino más bien a las dinámicas productivas que van reformulando los campos y método disciplinares.

Rama, Angel: Transculturación namativa de América Latina, Siglo XXI. Caracas. 1978; también, Rubén Dario y el Modernismo, Ediciones de la Biblioteca. Facultad de Humanidades y Educación. Lniversidad Central de Venezuela. 1970.

Me parece necesario destacar el hecho de que estas son formas del pensamiento eminentemente europeas y. más especificamente, francesas, por cuanto, contrario al sentido que se les ha pretendido atribuir, más bien retoman una tradición decimonónica que la década del sesenta del S. XX intentó revertir al esforzarse en construir teorías 'propiamente latinoamericanas'.
} 
de neurosis ${ }^{9}$. Por otro lado, esa crítica se presenta a sí misma como 'fundacional' en la medida en que niega a la tradición, sin percatarse, por otro lado, de que ese ha sido precisamente, uno de los rasgos distintivos de la historia del arte en América Latina que constituyen tradición.

En este sentido, me parece necesario destacar que los críticos latinoamericanos que se han plegado a esos aparatajes -Gerardo Mosquera, Nelly Richard. Andrea Giunta, Mónica Amor. Ticio Escobar, Maricarmen Ramírez entre otros ${ }^{11}$ - han descrito ese movimiento en un trabajo sobre el lenguaje que, al menos en un primer momento. pareció comportar una triple operación: una operación nominativa de conceptos que suponen una ampliación semántica del campo de sentidos de su contexto originario y que apunta a la evocación simbólica (lo que se ha dado en llamar la diferencia-borradura) de los rasgos caracterizadores de esas especificidades culturales; una resignificación de las categorias de la tradición crítica latinoamericana; y la 'encarnación' de tales operaciones en los modos expositivos del discurso, entendiendo por tales, la 'arquitectura' del tex to. En otras palabras, una estrategia reflexiva que asume un carácter plurívoco en la medida en que el discurso (en el sentido de Todorov "i se constituye, afín a la poética de los conceptualismos y postconceptualismos, en virtud de la convocatoria subjetiva de un lector, en apariencia, no necesariamente prefigurado.

Ahora bien. este proceso de la crítica se desplegó en un marco específico. Ya hemos señalado el rol que competió a las peculiares condiciones políticas que atravesó el cono sur. En otro sentido, ese marco lo constituyó la doble estrategia de consolidación de un sistema artístico ${ }^{12}$, y de inserción de artistas latinoamericanos en los circuitos europeos y estadounidenses que ya se verifica en la década del cincuenta. Así. se 'autorizaba' el campo artístico latinoamericano por la vía de la sincronicidad estética y, asimismo, se justificaba 'materialmente' la existencia misma de la crítica de artes. Vale la pena destacar aquí lo siguiente: si ese esfuerzo de la crítica por consolidar su rol social implicaba estrategias de posicionamiento, la crítica contemporánea ha multiplicado esas estrategias y las ha expresado, en cierta medida. como una especie de oposición generacional convirtiendo en una suerte de trofeo los espacios ocupacionales conquistados, cuestión que, por otra parte, no hace sino consolidar las redes de sentidos que fundamentan las instituciones que pretende criticar.

Otro elemento de ese marco lo constituyó sin lugar a dudas la condición de desmedro con que América Latina ingresa tanto a la sociedad de consumo como a las dinámicas globalizadoras que ella impulsó. En efecto, sólo con ese trasfondo (que por otro lado, no se interpretaba como 'mero trasfondo') puede comprenderse la orientación crítica de Marta Traba en Colombia, o la de Mario Pedrosa y Ferreira Gullar en el Brasil...

Retomando el carácter retórico que la transformación epistemológica ha asumido en América Latina, nos parece necesario destacar tanto el rol actualizador de la Historia del Arte como el esfuerzo de desautorización de la misma por la vía de su consideración como mero historicismo. En este sentido habría que señalar al menos dos aspectos: uno que dice relación con un movimiento europeo de reformulación de los aparatos cognoscitivos de la historia del arte en torno al Barroco ${ }^{13}$ y otro que señala un peculiar momento integratorio de disciplinas, protagonizado

\footnotetext{
${ }^{4}$ Morais, Frederico: Las artes plásticas en la América Latina: del trance a lo transitorio, Casa de las Américas, La Habana. 1990 (1979), pg. 5. Vale la pena considerar el hecho de que -contrariamente a la opinión de Morais- los movimientos transformatorios de la historia del arte en Europa, tanto aquellos de la primera mitad del siglo XIX como aquellos de la segunda mitad. cobran forma o pueden ser comprendidos bajo el signo de la pregunta por el 'origen'.

${ }^{10}$ Los críticos aquí referidos se encuentran reunidos en un volumen compilado por Gerardo Mosquera bajo el sugestivo título de Beyond the Fantastic. Contemporay Ant Criticism from Latin America. Institute of International Visual Arts. London. 1995, compuesto con textos tomados en su mayoría de diversos originales en español y que no cuentan, en cuanto volumen, con una versión en español.

${ }^{11}$ Todorov. Tzvetan: Simbolismo e interpretación. Monte Avila Editores. Caracas. 1992 (1982).

Algunos de los rasgos de ese esfucrzo los constituyeron la creación insistente de bienales a lo largo del continente y el ritmo vertiginoso de instalación de galerias en las grandes capitales.

${ }^{13}$ Recuérdense. por cjemplo, el sinnúmero de congresos abocados a la revalorización del Barroco y el Rococó a fines de los años cincuenta; o piénsese en el sentido del trabajo de Giulio Carlo Argan, Jan Bialostocki o Rosario Assunto. Incluso. me parece pertinente recordar la importancia otorgada por Hans R. Jauss a la disputa barroca entre 'clásicos y modernos', citada por Habermas en su conocido antículo 'La modernidad un proyecto inconcluso'.
} 
por la historia del arte latinoamericana, en torno a la definición de lo Barroco Americano y la necesidad, como en Europa, de reformular sus aparatos cognoscitivos si se pretendía orientarla hacia la pregunta por la identidad.

Uno de los terrenos en los cuales se desenvolvió esa estrategia fue la asunción de la Teoría de la Transculturación; no sólo por el nuevo enfoque que le asignaba al concepto mismo de cultura, sino especialmente por la estrategia simbólica que Ortiz articulaba en su Contrapunteo cubano del tabaco y el azúcar ${ }^{14}$. En este sentido, la incidencia de los planos míticos y religiosos en América Latina ha constituido centro de interés para esta nueva crítica, que ha logrado por esta vía perpetuar el 'exotismo' latinoamericano en lo que considera 'políticamente correcto', y que reinstala en la dialéctica naturaleza-artificio, una discusión que más bien debiera conducirse por la vía de la redefinición de las actuales condiciones y sentidos de la dependencia cultural y económica y de sus relaciones con la esfera del arte en un sentido pragmático. En efecto tales enfoques, como los de Ticio Escobar en el Paraguay, aspiran a desentrañar el sentido de la infinidad de mediaciones que supone un régimen cultural poscolonial, y en esa medida se presentan como un discurso fundacional y opositor a la tradición crítica en virtud del origen deconstructivista de su análisis. Por otro lado, la pretendida coincidencia formal (en el sentido de formalismo) de lo que constituye un plano linguístico, supone la plena autonomía de la esfera del arte en virtud de una reinstalación subterránea de las determinaciones espirituales en la voluntad de arte.

En este sentido, otro de los rasgos peculiares de la transformación epistemológica es su acusado ahistoricismo, vehiculado por un concentrado interés en la contemporaneidad-cosa que no nos parece negativa en sí misma- y que, por otra parte, supone la radical distancia con el pasado. Ciertamente, ello se expresa en la acusación proferida a la historia del arte (y atribuida a Benjamin) según la cual la condición narrativa de la historia del arte supone su incapacidad de 'reconstruir fidedignamente los hechos', cuestión que se pretende vincular a la imposibilidad de aprehensión del sentido desde Derrida. A partir de allí, se concluye que la historia pasa a pertenecer al género de la ficción, espacio que no tendría relación alguna con la praxis. Queda entonces, el crítico, liberado de la antigua y pesada carga de recabamiento y corroboración de datos, dado que nos estaría vedado, por definición, el acceso al origen ${ }^{15}$. Dicho sea de paso, me parece que hay aquí una radical transformación, y en cierto sentido, sustancial, con respecto a las estrategias críticas de las décadas previas (1950-1970), en donde el proceso de integración disciplinar fue experimentado en la Historia del Arte como una conversión de la obra en documento, documento de una época, de un mundo, y que exigía al historiador un gigantesco esfuerzo por diseñar aparatos metodológicos que le permitieran desentrañar los sentidos de las obras en el momento de su aparición. Estrategias al interior de las cuales se llevó a cabo la discusión en torno a la validez y pertinencia de categorías tales como las de 'reflejo' y 'analogía'.

Este último aspecto señala un cierto carácter -por qué no decirlo- perverso de las nuevas corrientes, dado que, estando vedado el origen, sólo nos queda asistir a los funerales de las especificidades culturales que se pretende custodiar y realizar los ritos pertinentes, puesto que, a pesar de que esos enfoques pretenden exponer esas diferencias culturales en un contex to dinámico, ese dinamismo se bosqueja por fuera de un marco procesual que permita comprender la naturaleza de la diferencia por fuera de las demasiado sobreentendidas relaciones de poder que inciden esencialmente en el comercio subjetivo con lo real, que se mantiene, por otra parte, convenientemente a distancia...

Este marco sintomático, brevemente referido, parece más bien dar cuenta de un cierto grado de confusión teórica que, en lugar de ofrecer un frente resistente al eurocentrismo que

\footnotetext{
Ortiz. Fernando: Contrapunteo cubano del tabaco y el azúcar varias ediciones: nosotros consultamos la de Biblioteca Ayacucho. Caracas, 1980

De hecho es ejemplificador el hecho de que, en el encuentro internacional sobre Políticas y estéticas de la memoria'. ralizado en Santiago de Chile en 1999. fueron prácticamente excluidos los historiadores.
} 
pretende declarar, se constituye en un nuevo momento. más sofisticado sin duda. de inserción ideológica a la Metrópoli. En el terreno de la crítica de artes visuales en América latina. las estrategias de actualización de los sustratos de sentido vehiculados por esos aparatos son, como hemos visto, de variada índole; pero. en definitiva, van concluyendo en el mismo lugar: Ja exacerbación de la sacrosanta autonomía del arte. parafraseando a Francastel, y. en la aproximación a lo real, la plena independencia de la esfera teórica de aquella de la praxis. 